\title{
An evaluation of repeat intra-articular injections of yttrium-90 colloids in persistent synovitis of the knee
}

\author{
J. WINFIELD AND J. M. GUMPEL
}

From the Rheumatic Diseases Study Group, Northwick Park Hospital, Harrow

SUMmARY The effectiveness of a second intra-articular injection of yttrium-90 colloid was studied in 30 patients with persistent synovitis of the knee. All had responded poorly to a first injection of yttrium-90 yet seemed likely to benefit from this therapy. With a minimum review period of 6 months complete remission of synovitis was obtained in $20 \%$, while $63 \%$ gained symptomatic relief, with some reduction of synovitis. No improvement occurred in $17 \%$, and in this group generalised disease activity was more apparent.

Radiocolloids now have a useful role in the management of chronic synovitis, and the use of yttrium-90 in the knee has increased considerably. Various controlled trials in rheumatoid arthritis have shown that yttrium-90 is superior to saline (Bridgman et al., 1973), to hydrocortisone (Delbarre et al., 1974), and to osmic acid and a long-acting steroid, triamcinolone hexacetonamide (Menkes et al., 1977). A randomly selected comparison of irradiation and surgical synovectomy showed little difference after 2 years (Gumpel and Roles, 1975), and irradiation is probably the treatment of choice in the older patient. Nonetheless in long-term studies of such irradiated patients (Gumpel, 1977) some $28 \%$ failed to improve or derived transient improvement only.

A second injection has not previously been favourably considered. We have evaluated the results of second injections in patients with poor response to the initial injection, in whom the original indications for intra-articular irradiation still seemed valid: active synovitis apparently confined to the joints to be treated with poor response to steroid injection.

\section{Patients and criteria for selection}

At Northwick Park Hospital the criteria for the selection, injection procedure, and dosage of radioisotope in the knee have been relatively standard for a number of years (Gumpel, 1973). The patient Presented at the combined meeting of the British Association of Rheumatology and Rehabilitation and the Heberden Society and the Section of Rheumatology and Rehabilitation of the Royal Society of Medicine at Carlisle, 1977

Accepted for publication 19 May 1978

Correspondence to Dr J. M. Gumpel, Northwick Park Hospital, Watford Road, Harrow, Middlesex HA1 3UJ
Table 1 Details of patients

\begin{tabular}{lc}
\hline Diagnosis & No. \\
\hline Rheumatoid arthritis & 26 \\
Psoriatic arthritis & 2 \\
Ankylosing spondylitis & 1 \\
Osteoarthrosis with recurrent hydroarthrosis & 1 \\
\hline Male/female ratio & $11: 19$ \\
Mean age & $61 \cdot 7 \mathrm{yr}$ \\
Mean duration of knee symptoms prior to yttrium-90 & $7 \cdot 8 \mathrm{yr}$ \\
Mean time lapse between 1st and 2nd injection & $9 \cdot 2 \mathrm{months}$ \\
Number of knees treated & 46 \\
\hline
\end{tabular}

should be at least 45 years of age and should have symptoms and signs of active synovitis rather than of articular damage. Those patients with marked articular damage without synovitis or with widespread active synovitis should be excluded.

The clinical details of the 30 patients with persistent synovitis of the knee who had responded poorly to a first injection of $5 \mathrm{mCi}$ of yttrium-90 are given in Table 1. Each patient had been followed up for some 6 months after the first injection and still fulfilled the basic criteria for selection outlined above.

Although the usual initial and repeat injections were of $5 \mathrm{mCi}$ of yttrium-90, occasional patients had initially been injected with $7 \cdot 5,6$, or $4 \mathrm{mCi}$ of yttrium-90, and occasional repeat injections were of $2.5 \mathrm{mCi}$ depending on an assessment of the degree of synovitis. The radiocolloid used depended on availability. Initially the resin was used, then citrate and ferric hydroxide; since 1974 the silicate has been used exclusively.

Patients were admitted to hospital and a standard assessment proforma was used (Table 2). They were followed up routinely and reassessed with the use of the standard proforma. This study does not include 
Table 2 Proforma for assessment of patients

\begin{tabular}{ll}
\hline Global assessment & Knee assessment \\
\hline $\begin{array}{l}\text { Length of morning stiffness } \\
\text { (minutes) }\end{array}$ & $\begin{array}{l}\text { Morning and immobility stiffness } \\
\text { (minutes) } \\
\text { Effusion and synovial thickening } \\
\text { recorded on a 0, }+,++ \text { scale } \\
\text { The presence of a Baker's cyst and } \\
\text { its size }\end{array}$ \\
Grip strength & $\begin{array}{l}\text { Range of movement (degrees) } \\
\text { Instability of the knees recorded on } \\
0,+,+ \text { scale }\end{array}$ \\
Walking times & $\begin{array}{l}\text { Circumferential measurements of } \\
\text { the knee at } 3 \text { levels: }\end{array}$ \\
Raemoglobin and ESR & $\begin{array}{l}\text { Mid patellar, } 3 \text { cm, and } 15 \mathrm{~cm} \\
\text { above the superior border of the } \\
\text { patella. }\end{array}$ \\
\hline
\end{tabular}

any patients started on disease-modifying drugs (for example, gold, penicillamine) after the first injection.

\section{Results}

The results of repeat assessments showed that 9 knees in 6 patients had complete resolution of synovitis. A moderate improvement occurred in 28 knees in 19 patients. No improvement was obtained in 9 knees in 6 patients. The features of the 3 groups are presented in detail.

\section{COMPLETE RESOLUTION OF SYNOVITIS}

All had polyarticular rheumatoid arthritis. One had a positive rheumatoid factor test (seropositive), while the remaining 5 patients were seronegative. The mean duration of synovitis of the knees prior to second injection was $6 \cdot 8$ years and the mean time lapse between first and second injections was $8 \cdot 5$ months. Each patient improved within 3 months after the second injection. The mean ESR over the whole assessment period was $21 \mathrm{~mm}$ in the first hour with a range of $8-40 \mathrm{~mm}$. The general disease state in these patients was satisfactorily maintained on a conventional nonsteroidal anti-inflammatory drug regimen without alteration during the whole assessment period. Two of these patients were on maintenance gold therapy throughout.

Four patients remained symptom-free at 17 months, 18 months, 3 years, and 5 years after repeat injection. Another remained symptom-free in the knees until her death from carcinomatosis 11 months after repeat injection, the primary neoplasm having been diagnosed before yttrium-90 therapy. The sixth is symptom-free without synovitis 9 months after repeat injection.

\section{MODERATE IMPROVEMENT}

These patients considered the procedure to have been a success, with a reduction of pain and stiffness and frequently an improvement in walking ability, though synovial thickening and effusion did not? disappear. In this group 15 patients had rheumatoid arthritis and seven were seropositive, while eight were seronegative. One had osteoarthrosis witlo recurrent hydroarthrosis; one patient had ankylosing spondylitis; two had psoriatic arthritis. All the patients with rheumatoid arthritis had polyarticula尺 disease; the remaining patients had monoarthritisक The mean duration of knee synovitis before firs 5 injection was $7 \cdot 8$ years, and mean time lapse betweenfirst and second injection was $7 \cdot 3$ months.

The earliest improvement came within 2 months but in most cases improvement was apparent by months. The improvement was of varied duration $\omega_{\infty}$ Two patients improved only after 12 months. Herị it is not possible to attribute improvement to yttrium-90 alone, as there were alterations in drug regimens which correlated with symptomatic improvement. The mean ESR of those with rheumatoid arthritis was $57 \mathrm{~mm}$, ranging from 21 to $127 \mathrm{mmo}$ The patients with ankylosing spondylitis or psoriasis did not fare differently from those with rheumatoide arthritis.

\section{NO IMPROVEMENT}

In this group the activity of general disease on globa男 assessment appeared greater in all 5 patients tha in those in the other groups. All had rheumatoi arthritis and all were seropositive, though the mea ESR in this group was only $44 \mathrm{~mm}$, range $23-70 \mathrm{~mm}$ 을

The mean duration of knee synovitis was $8 \cdot 8$ years, and the mean time lapse between first an second injection was 11.8 months. Two patient had alterations in their drug regimen: 1 an increase dosage of gold, another an increase in dosage of penicillamine. These alterations produced a transient. improvement in symptoms only which had little effect on the irradiated knee. One patient in this group had severely damaged knees and would have been better treated by arthroplasty.

\section{Discussion}

Intra-articular irradiation of the synovium is con sidered to be of considerable value in the manage ment of rheumatoid arthritis. Patients with pere sistent synovitis due to psoriatic arthropathy and ankylosing spondylitis may also benefit from thi therapy.

One definite advantage of irradiation over surgical synovectomy is that it can be easily repeated and our experience with second injections has beem favourable. We considered that a formal review of our second injections, albeit retrospective and une controlled, would be useful. A second yttrium-9 
injection may be effective even in patients in whom a previous injection has not been effective. However, the overall results of second injections are not as good as those of first injections.

Care in selection of suitable patients is important. Unfortunately, objective methods of assessing general disease activity are remarkably poor, and the various articular indices are a poor guide in selecting suitable patients. For example, the methods of assessment of knee synovitis are relatively imprecise, though xeroradiography of the knee (Gumpel et al., 1978) may help to give more objective measurements. Similarly the ESR was not particularly helpful, the mean level being higher in those with some response to yttrium-90 than in those with no response. In this study clinical grading of synovial thickening and effusion size was the best assessment, together with the patient's subjective impression.

Simple circumferential measurements of the knee may be useful, but in the presence of effusions the measurements are subject to considerable variation (Kirwan et al., 1978). In addition changes in body weight of $7 \mathrm{lb}(3.2 \mathrm{~kg})$ or more between measurements may obscure real changes in circumferential measurements of the knee.

It has been suggested that patients with psoriasis fare less well than patients with rheumatoid arthritis (Menkes et al., 1972), but in this study, though numbers were small, this was not confirmed. Patients with psoriasis and ankylosing spondylitis improved similarly to those in the rheumatoid arthritis group.

Varying doses of yttrium-90 have been used in the knee. Bridgman et al. (1973) used $3 \mathrm{mCi}$, while Menkes used $4 \mathrm{mCi}$ after trying 3, 4, and $6 \mathrm{mCi}$. Daymond et al. (1977) compared 5 and $8 \mathrm{mCi}$ of yttrium-90 and found no significant difference in their results either clinically or after technetium scanning and have therefore adopted the lower dosage of $5 \mathrm{mCi}$. Kerschbaumer et al. (1977) also stressed the use of a small dose of yttrium- 90 after reporting marked degenerative change in human chondrocytes after $5 \mathrm{mCi}$ yttrium-90. This appears to confirm the suspected risk of cartilage necrosis, but as there was no control group the observed cartilage damage may have been a normal sequel to chronic synovitis. It is possible that better results may be obtained by repeat small doses of yttrium- 90 rather than using an initial larger dose. The situation is similar to that experienced in assessing dosage of radioiodine in the treatment of hyperthyroidism where 2,3 , or even 4 doses of iodine-131 may be required, and attempts to predict the right dosage for each patient have been largely unsuccessful.

Synoviorthesis is a relatively cheap, painless, and easily repeatable technique, but it is important that the basic criteria for selection of patients are observed, including a prior trial of intra-articular corticosteroid.

It is a pleasure to record the assistance of Mrs Monica Fisher of the Radioisotopes Department.

\section{References}

Bridgman, J. F., Bruckner, F., Eisen, V., Tucker, A., and Bleehen, N. M. (1973). Irradiation of the synovium in the treatment of rheumatoid arthritis. Quarterly Journal of Medicine, 42, 357-367.

Daymond, T. J., Thompson, M., Hussain, M. A., and Clayton, B. (1977). Synoviorthèse of the knee by yttrium90. Abstract No. 603. International Congress of Rheumatology. San Francisco.

Delbarre, F., Le Go, A., Menkes, C., and Aignon, M. (1974). Preuve par étude statistique en double aveugle de l'effet thérapeutique du colloide charge d'yttrium radioactif (90Y) dans l'arthrite rheumatoide. Comptes Rendus Hebdomadaires des Scéances de l'Académie des Sciences, 279, Serie D, 1051-1054.

Gumpel, J. M. (1973). Review of published and personal results. Annals of the Rheumatic Diseases, 32, Supplement to No. 6, 29-33.

Gumpel, J. M. (1977). Synoviorthèse: surgical or medical? In Rheumatoid Arthritis. Edited by J. L. Gordon and B. L. Hazleman. Elsevier/North Holland Biomedical Press: Amsterdam.

Gumpel, J. M., Matthews, S. A., and Wilkins, R. A. (1978). Is xeroradiography an objective assessment in synovitis of the knee? In preparation.

Gumpel, J. M., and Roles, N. C. (1975). A controlled trial of intra-articular radiocolloids versus surgical synovectomy in persistent synovitis. Lancet, 1, 488-489.

Kerschbaumer, F., Falser, N., and Bauer, R. (1977). Synoviorthesis: therapeutic value, side effects on human cartilage. Abstract No. 610. International Congress of Rheumatology. San Francisco.

Kirwan, J. R., Byron, M. A., Winfield, J., Altman, D., and Gumpel, J. M. (1978). Circumferential measurements of the knee. In preparation.

Menkes, C. J., Aignon, M., Galmiche, B., and Le Go, A. (1972). Le traitement des rheumatismes par les synoviorthèses. Rhumatologie, 2, Supplement, 61-80.

Menkes, C. J., Le Go, A., Verrier, P., and Delbarre, F. (1977). A controlled trial of intra-articular yttrium 90 , osmic acid and triamcinolone hexacetonide in rheumatoid arthritis. Abstract No. 614. International Congress of Rheumatology, San Francisco. 